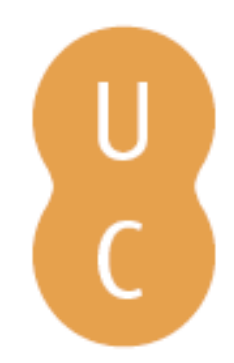

\title{
nommalina
}

\section{Avaliação de solos residuais de rochas basálticas e a ocorrência e feições erosivas (trópico de Capricórnio, sul do Brasil)}

\author{
Autor(es): $\quad$ Souza, M. L. de; Souza, V. de \\ Publicado por: Imprensa da Universidade de Coimbra \\ URL \\ persistente: URI:http://hdl.handle.net/10316.2/31436 \\ DOI: $\quad$ DOI:http://dx.doi.org/10.14195/978-989-26-0531-9_14 \\ Accessed : $\quad$ 26-Apr-2023 15:57:47
}

A navegação consulta e descarregamento dos títulos inseridos nas Bibliotecas Digitais UC Digitalis, UC Pombalina e UC Impactum, pressupõem a aceitação plena e sem reservas dos Termos e Condições de Uso destas Bibliotecas Digitais, disponíveis em https://digitalis.uc.pt/pt-pt/termos.

Conforme exposto nos referidos Termos e Condições de Uso, o descarregamento de títulos de acesso restrito requer uma licença válida de autorização devendo o utilizador aceder ao(s) documento(s) a partir de um endereço de IP da instituição detentora da supramencionada licença.

Ao utilizador é apenas permitido o descarregamento para uso pessoal, pelo que o emprego do(s) título(s) descarregado(s) para outro fim, designadamente comercial, carece de autorização do respetivo autor ou editor da obra.

Na medida em que todas as obras da UC Digitalis se encontram protegidas pelo Código do Direito de Autor e Direitos Conexos e demais legislação aplicável, toda a cópia, parcial ou total, deste documento, nos casos em que é legalmente admitida, deverá conter ou fazer-se acompanhar por este aviso.

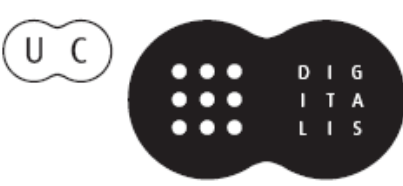





\title{
AVALIAÇÃO DE SOLOS RESIDUAIS DE ROCHAS BASÁLTICAS E A OCORRÊNCIA DE FEIÇÓES EROSIVAS (TRÓPICO DE CAPRICÓRNIO, SUL DO BRASIL)
}

\author{
EVALUATION OF RESIDUAL SOILS OF BASALTIC ROCKS \\ AND THE OCCURRENCE OF EROSIVE FEATURES \\ (TROPIC OF CAPRICORN, SOUTH OF BRAZIL)
}

\author{
M. L. de Souza ${ }^{1} \&$ V. de Souza ${ }^{2}$
}

\begin{abstract}
Resumo - O presente artigo apresenta os resultados obtidos através de pesquisas experimentais integradas, que foram desenvolvidas visando o levantamento de algumas propriedades físicas de solos residuais de rochas basálticas. A finalidade foi avaliar se essas propriedades naturais, aliadas a outros atributos do meio físico, interferem diretamente ou não no desenvolvimento de feiçôes erosivas de grande porte designadas de "gullies" e denominadas de voçorocas ou boçorocas no Brasil. A área de estudo localiza-se em um campo experimental da Universidade Estadual de Maringá, nas coordenadas 2323'56"

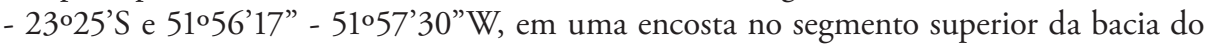
Córrego Mandacaru, lado esquerdo, situada na cidade de Maringá, estado do Paraná, Sul do Brasil, onde se encontra a linha imaginária do Trópico de Capricórnio. Os ensaios realizados em campo e laboratório foram: análise morfopedológica, infiltração pelo método do duplo anel, granulometria conjunta, erodibilidade e adsorção do corante azul de metileno utilizado em fraçóes finas do solo como um indicativo do grau de atividade dos argilominerais. Além desses ensaios, também foram elaborados documentos cartográficos. Dos resultados obtidos concluímos que os atributos do meio físico analisados não interferem diretamente no desenvolvimento de feiçóes erosivas de grande porte, mas podem ser afetados pela interferência das atividades humanas, concretamente a concentração do volume das águas das chuvas ou a remoção, ou não, do coberto vegetal.
\end{abstract}

Palavras-chave - Solos residuais; erosão; basaltos; Maringá

${ }^{1}$ Dep. Geografia e Programa de Pós-graduação em Geografia, Universidade Estadual de Maringá, Bloco J-12, 87020-900, Maringá, Paraná, Brasil; mlsouza@uem.br

${ }^{2}$ Geógrafo autônomo; vladimirdesouza@yahoo.com.br 
Abstract - The current essay shows the results from integrated experimental research based on the physical qualities of residual soils from basaltic rocks. These natural features from the physical environment were evaluated to check whether they interfered directly or indirectly in the development of gullies (voçorocas in Portuguese). Study area lies within the experimental field of the Universidade Estadual de Maringá, Maringá (PR), Brazil, at 23023'56" - 2325'S and 51056'17" - 51057'30"W, on a slope in the upper, left segment of the Mandacaru stream basin, in Maringá (PR), Brazil, standing over the Tropic of Capricorn imaginary line. The field and laboratory essays were as follows: morphopedological analysis, double ring method infiltration, joint granulometry, erosion capacity and adsorption of methylene blue staining in fine soil fractions as an indication of clay-mineral activity degree. Apart from the above mentioned essays, cartographic documents were also undertaken. The obtained results show that the analyzed physical environment features do not directly affect the development of gullies, but are rather due to the interference of human activities, namely, the concentration of rain water volume and the removal or non-removal of vegetation covering.

\section{Keywords - Residual soils; Erosion; Basalt; Maringá}

\section{1 - Introduçáo}

O solo é um recurso natural de suma importância para a vida humana. O estudo e o conhecimento de suas propriedades constituem uma ferramenta fundamental para diversos ramos das Ciências Naturais. Os solos residuais, enfoque da pesquisa, são formados por diferentes processos de intemperismo e pedogênese que atuam sobre as rochas e que levam à constituição de um perfil de alteração de rocha, por vezes complexo. Embora a análise de um perfil de solo residual possa ter restriçóes quanto a sua generalização regional, alguns fatores devem ser considerados na análise local como a espessura dos materiais.

A pesquisa teve como principal objetivo a realizaçáo de um levantamento de algumas propriedades físicas de solos residuais de rochas basálticas. A finalidade foi avaliar se essas propriedades naturais, aliadas a outros atributos intrínsecos e extrínsecos do meio físico, afetam diretamente ou não o desenvolvimento de feiçôes erosivas de grande porte, denominadas voçorocas ou boçorocas no Brasil e "gullies" nos países de língua inglesa.

O interesse no assunto surgiu devido aos relatos da presença desse tipo de feição erosiva em áreas urbanas da cidade de Maringá nos últimos anos.

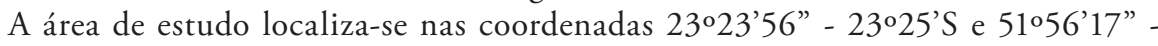
$51^{\circ} 57^{\prime} 30^{\prime} \mathrm{W}$, em uma encosta no segmento superior da bacia do Córrego Mandacaru, lado esquerdo, situada na cidade de Maringá, estado do Paraná, Brasil, onde se encontra a linha imaginária do Trópico de Capricórnio (Fig. 1). O local pertence à Universidade Estadual de Maringá, Centro de Treinamento em Irrigação, destinado a vários tipos de experimentos em campo devido à disponibilidade de perfis característicos dos diferentes tipos de solos da regiáo e de diversos tipos de cobertura vegetal. É um local utilizado principalmente para pesquisas agronômicas, assim como para pesquisas de Geociências. Sendo assim, algumas pesquisas de iniciação científica foram desenvolvidas nessa área com a temática abordada no presente artigo (BALBO, 2004; VIEIRA, 2004; SCHIMIDT, 2008). 


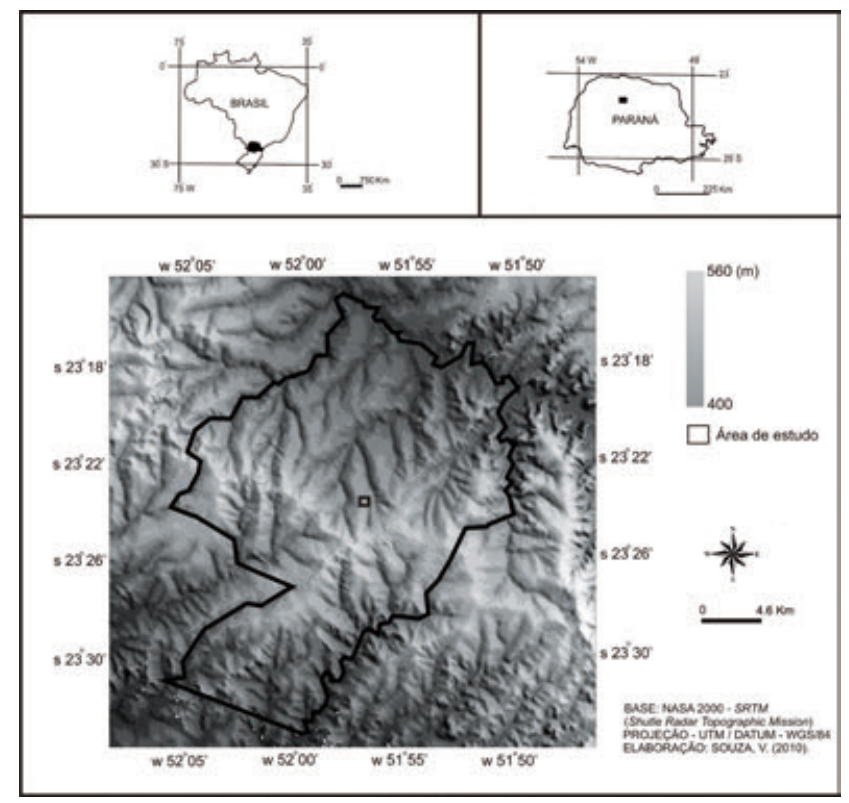

Fig. 1 - Localizaçáo da área de estudo.

\section{2 - Importância dos estudos de solos residuais para análises de feiçóes erosivas}

No território brasileiro ocorre o predomínio de solos profundos, ferralíticos e porosos ou lateritas. São materiais que encontram-se sobre as plataformas geomorfológicas que estão expostas à aproximadamente $80 \mathrm{Ma}$ a elevados índices termo-hídricos.

No sul do Brasil, em especial no norte do estado do Paraná, os solos residuais de rochas basálticas são profundos, bem drenados, apresentam alta fertilidade natural e são intensamente utilizados para fins agrícolas. Devido ao processo histórico de ocupação e das características climáticas da referida região, observa-se um intenso processo de degradação dos solos, sobretudo por fenômenos erosivos hídricos.

No sul do Brasil, em especial no norte do estado do Paraná, os solos residuais de rochas basálticas são profundos, bem drenados, apresentam alta fertilidade natural e são intensamente utilizados para fins agrícolas. Devido ao processo histórico de ocupação e das características climáticas da referida região, observa-se um intenso processo de degradação dos solos, sobretudo por fenômenos erosivos hídricos.

Os principais fatores que influenciam as perdas de solo por erosão são a chuva, a cobertura vegetal, o uso da terra, a topografia e as características dos solos (MORGAN, 1995). Nesse sentido, o levantamento dos parâmetros físicos, morfológicos e mineralógicos é fundamental no estudo dos solos tropicais, pois irá fornecer informaçôes relevantes para o processo de uso e ocupação dessas terras.

Atributos físicos como a textura, a capacidade de infiltração, a profundidade dos solos e os fatores relacionados à resistência dos constituintes ao destacamento irão determinar a suscetibilidade dos solos à erosão (SCOTT, 2000). 
Em condiçóes tropicais, os solos que se desenvolvem a partir de rochas areníticas apresentarão materiais mais grosseiros em sua composição, enquanto nos solos desenvolvidos sobre rochas vulcânicas básicas predominarão as fraçôes finas. A identificação dos principais constituintes mineralógicos da fração fina pode assessorar no entendimento do comportamento da estabilidade dos materiais argilosos em contato com a água, durante os processos de destacamento das partículas (SOUZA \& GASPARETTO, 2010).

De acordo com REZENDE et al. (2005), se um solo apresentar argilominerais trilaminares do grupo 2:1 com características expansivas, com a introdução de moléculas polares, o seu comportamento frente aos processos erosivos será diferente, ou seja, durante o processo de erosão hídrica, as partículas de argila irão se expandir proporcionando maior desagregação.

\section{3 - Procedimentos metodológicos}

No desenvolvimento da presente pesquisa foram adotados procedimentos metodológicos de diversos autores que realizaram uma revisão bibliográfica do tema e da área de estudo, e que incluem o levantamento de dados em campo e em laboratório, além da elaboração de documentos cartográficos descritos a seguir. A área na qual os ensaios foram realizados foi escolhida para essa análise devido aos seguintes fatores: encosta representativa de perfil típico de alteração da região, acesso fácil e infraestrutura básica disponível, como o fornecimento de água para os ensaios de infiltração.

\section{1 - Coleta de dados em campo}

Primeiramente foi realizada a caracterização do meio físico da encosta estudada, representada por um perfil (topossequência) que apresenta $540 \mathrm{~m}$ de comprimento com um desnível de $52 \mathrm{~m}$, do topo ao talvegue do vale (Fig. 2). Na sequência foi realizada a demarcação dos pontos de coleta de amostras de solo, deformadas e indeformadas e ensaios de campo (P1, P2 e P3). O GPS (Global Positioning System) foi utilizado para determinar a latitude, a longitude e a altitude dos pontos, ou seja, foram feitas as aberturas de duas trincheiras (P1 e P2) para análises dos solos residuais nos segmentos superior (altitude: $520 \mathrm{~m}$ ) e mediano (altitude: $480 \mathrm{~m}$ ). A terceira trincheira (Ponto 3), definida no segmento inferior, (altitude: $460 \mathrm{~m}$ ) foi aberta somente para finalizar o perfil da encosta, pois os materiais expostos náo pertencem a classe de solos residuais.

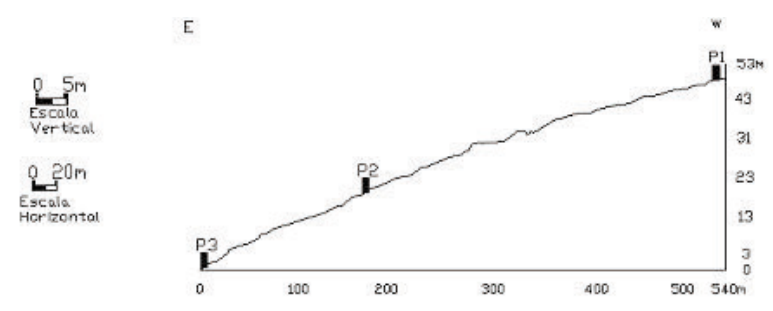

Fig. 2- Perfil esquemático da topossequência do local estudado. 
Os ensaios realizados em campo, segundo as metodologias de LEMOS \& SANTOS (1996) e MUNSELL (1975) foram: sondagens a trado manual para análise pedológica básica das características morfológicas dos solos (cor, textura, estrutura, porosidade, cerosidade, consistência, cimentação, nódulos e concreçôes minerais, conteúdos de carbonatos e eflorescências); também foram realizados ensaios de infiltração pelo método do duplo-anel (ASTM-D 3385-88, 1988).

\section{2 - Ensaios em laboratório}

Os ensaios realizados em laboratório nos solos residuais foram: granulometria para determinar a textura do solo (CAMARGO et. al., 1986) e erodibilidade que reflete a sua maior ou menor susceptibilidade à ação erosiva. $\mathrm{O}$ método adotado para essa propriedade foi o conjunto de ensaios de absorção de água (S) e perda de massa por imersão (P). Os resultados foram obtidos a partir da aplicação dos valores adquiridos nos ensaios de laboratório na seguinte equação: $\mathrm{E}=40 \mathrm{~S} / \mathrm{P}$, onde: $\mathrm{E}=$ erodibilidade; $\mathrm{S}$ e $\mathrm{P}$ são valores determinados pelos ensaios realizados em laboratório; onde: $\mathrm{E}>1$ = baixa erodibilidade e $\mathrm{E}<1=$ alta erodibilidade (PEJON, 1992).

O ensaio da adsorção do corante azul de metileno pelo método da mancha, adaptado por PEJON (1992), foi realizado com o objetivo de analisar expeditamente, o grau de atividade dos argilominerais nas fraçóes finas dos solos, ou seja para detectar a existência ou não de argilominerais com comportamento expansivo, que podem colaborar diretamente com a desagregaçáo acelerada das partículas dos solos e que podem causar vários tipos de feiçóes erosivas.

\section{3 - Documentos cartográficos}

Em gabinete foram elaboradas as cartas de localização com o modelo de elevação da região, utilizando-se imagens de radar SRTM (Shuttle Radar Topography Mission). Além da elaboração de gráficos que representaram as curvas de infiltração, efetuou- se o cálculo das Velocidades de Infiltração acumulada e média (VIa e VIm) em cm/h, segundo BERNARDO (1986).

\section{4 - Resultados}

\section{1 - Caracterização do meio físico-natural}

O substrato rochoso da área é composto por rochas vulcânicas da Formação Serra Geral, formadas pelo vulcanismo fissural ocorrido no período Juro-Cretáceo. Os derrames com espessuras variáveis de alguns metros a uma centena de metros, podendo chegar a $1000 \mathrm{~m}$ no centro da bacia, apresentam alternância de níveis maciços e vesiculares e/ou amigdaloidais, também de espessuras variadas (PINESE \& NARDY, 2003). 
$\mathrm{Na}$ área ocorre o predomínio de rochas basálticas que sofreram um intenso processo de intemperismo, principalmente químico, que gerou um manto de alteração com camadas de até $30 \mathrm{~m}$ de profundidade, segundo NÓBREGA et al. (2010). Estes analisaram vários ensaios de SPT (Standard Penetration Test) realizados em vários locais da cidade onde está inserida a área de estudo. Os autores destacaram que a porção maciça das rochas apresenta resistência mecânica mais elevada e, normalmente, é mais resistente ao intemperismo químico, que aquelas vesiculares e/ou amigdaloidais. Sendo assim foi utilizada uma escala de graus de alteração da rocha, segundo critérios de campo adaptáveis (GEOLOGICAL SOCIETY ENGINEERING GROUP WORKING PARTY REPORT, 1990). Os graus de alteração encontrados no local foram: intensamente (IV), completamente (V) e o solo residual (VI), o objeto de estudo.

Do ponto de vista pedológico, o solo residual oriundo de rochas basálticas foi classificado, segundo EMBRAPA (1999), como Latossolo Vermelho férrico que ocorre, em geral, no topo e no segmento superior das encostas. No segmento mediano, e por vezes no topo, predomina o Nitossolo Vermelho férrico, ambos podem ser distroférrico ou eutroférrico, e em espessuras rasas, predominam os Cambissolos e Neossolos Litólicos. Os Gleissolos predominam no segmento inferior.

Geomorfologicamente, a área encontra-se inserida no Terceiro Planalto Paranaense, apresenta relevo suave ondulado com encostas convexo-retilíneas e posiciona-se no divisor das bacias dos rios Pirapó e Ivaí (MAACK, 1968). Na área de estudo ocorrem várias nascentes do Córrego Mandacaru, que pertence à bacia do Rio Pirapó, a principal fonte de abastecimento de água para a cidade de Maringá. A variação altimétrica regional está entre 400 a $560 \mathrm{~m}$ acima do nível do mar e as classes de declividade variam de 3 a $20 \%$, com predomínio na área de 3 a $8 \%$. No local perpassa o Trópico de Capricórnio e o clima predominante é o subtropical úmido mesotérmico (Cfa), com tendências de chuvas no verão (dezembro a março) e inverno (junho a setembro) e com geadas pouco frequentes sem estação seca definida (KÖEPPEN, 1948). Apresenta um índice pluviométrico anual de $1.500 \mathrm{~mm}$, umidade relativa do ar em torno de $66 \%$ e temperatura média em torno de $22^{\circ} \mathrm{C}$. A média das mínimas é $10,3^{\circ} \mathrm{C}$ e a média das máximas $33,6^{\circ} \mathrm{C}$.

A vegetação original do local era constituída pela Floresta Estacional Semidecidual e Submontana. O desenvolvimento da floresta era condicionado pela dupla estacionalidade climática, com épocas de intensas chuvas de verão e estiagens prolongadas. (MAACK, 1968).

Atualmente, o uso da terra é caracterizado por infraestrutura de edificaçóes do CTI. No local dos ensaios predominam gramíneas ao longo da encosta, áreas destinadas ao cultivo de culturas permanentes ou temporárias, dependendo do experimento desenvolvido, e mata ciliar alterada nas margens do Córrego Mandacaru (Fig. 3). A presença de sulcos erosivos foi observada na área, principalmente nos locais onde os solos residuais estavam expostos e em alguns trechos nas margens do córrego, onde predominam os Gleissolos. 


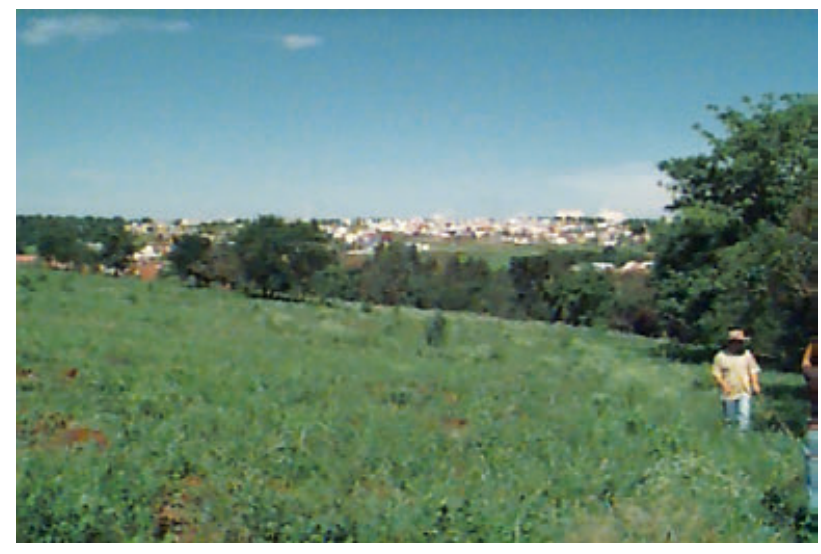

Fig. 3- Vista da área de estudo.

\section{2 - Propriedades físicas dos solos residuais no campo experimental}

Do ponto de vista pedológico, os solos residuais do perfil de alteração foram classificados no segmento superior (P1) como Nitossolo Vermelho distroférrico, latossólico, textura argilosa. No segmento mediano (P2), como Nitossolo Vermelho eutroférrico, textura argilosa. E para concluir o perfil (P3), no sopé da encosta ocorrem solos com hidromorfia, no caso Gleissolo, pouco húmico (Fig.4).

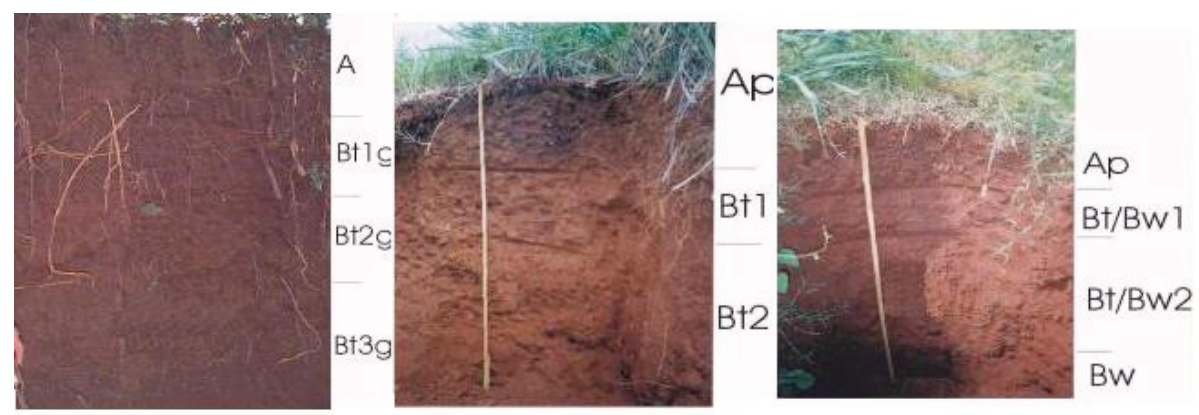

Fig. 4 - Representação dos horizontes dos solos (P3, P2 e P1, da esquerda para direita).

Sinteticamente, segundo EMBRAPA (1999), a classe Nitossolo Vermelho, compreende solos minerais, não hidromórficos, com horizonte B nítico, formados a partir de rochas eruptivas básicas. Estes solos são profundos, argilosos, bem drenados, com argilas de baixa capacidade de troca catiônica, predominantemente cauliníticos, ricos em sequióxidos de ferro e alumínio, com expressiva cerosidade na superfície dos agregados e com sequência de horizonte $\mathrm{A}, \mathrm{B}$ nítico e $\mathrm{C}$.

Para corroborar com a textura da análise morfopedológica foram feitos ensaios de granulometria (BALBO, 2004) que resultaram nos seguintes gráficos (Fig.5): 


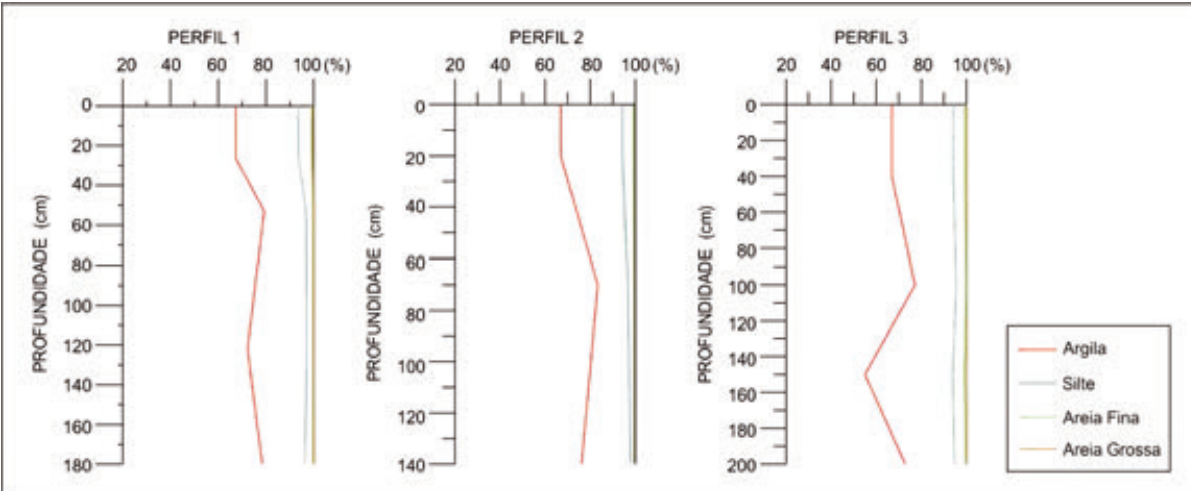

Fig. 5- Gráficos representativos dos ensaios granulométricos.

Nos dois pontos (P1 e P2) de análise dos solos residuais, predomina a textura de argilosa a muito argilosa, que também foi encontrada no $\mathrm{P} 3$.

VIEIRA (2004) realizou nos mesmos locais dos perfis de alteração, ensaios expeditos com o corante azul de metileno nas fraçôes finas dos solos, após a percepção táctil-visual, que indicou a presença de materiais argilosos, fato comprovado em laboratório, como explicitado acima. Os resultados obtidos mostraram que no P1, os Coeficientes de Atividade (CA) foram de 54,9\% no horizonte de maior incidência e de 37,95 no de menor. No P2, os valores de CA foram muito próximos, o de maior incidência foi de $49,9 \%$ e de $45,9 \%$ no de menor incidência. Durante o trabalho de interpretação dos valores de CA obtidos, constatou-se que a encosta analisada apresenta possivelmente argilominerais pertencentes ao grupo da caulinita. Esse resultado expedito foi comparado com alguns dados obtidos por SOUZA \& GASPARETTO (2010), que realizaram análises de difratometria de raios-X nos mesmos tipos de solos na região, e que obtiveram a presença de argilominerais do grupo da caulinita e óxidos.

Os ensaios de erodibilidade realizados nos mesmos locais resultaram em E > 1, ou seja, no P1 $(1,8)$ e no P2 $(1,9)$ e apresentaram baixa erodibilidade devido ao teor da fração argila presente nos solos residuais oriundos das rochas basálticas. O detalhamento dos ensaios realizados pode ser pesquisado em BALBO (2004).

$\mathrm{O}$ comportamento da propriedade infiltração encontrado foi o característico de materiais argilosos com baixas velocidades de infiltração. A velocidade básica de infiltração obtida para os dois ensaios nos pontos 1 e 2 foi de $0,9 \mathrm{~cm} / \mathrm{h}$. A figura 6 mostra o comportamento das curvas de Velocidade de Infiltração acumulada e média VIa $(\mathrm{cm} / \mathrm{h})$ e $\operatorname{VIm}(\mathrm{cm} / \mathrm{h})$ no decorrer do tempo de ensaio. 


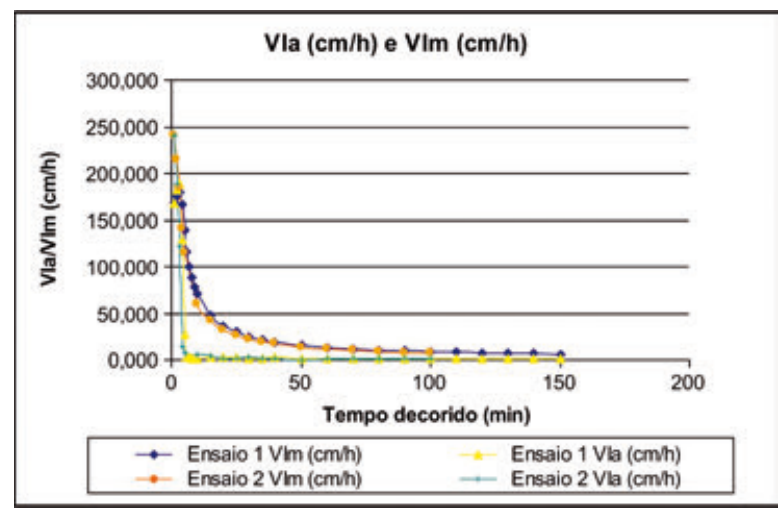

Fig. 6- Gráfico das Velocidade de Infiltração acumulada e média da área de estudo (SCHIMIDT, 2008).

\section{5 - Conclusóes}

A caracterização básica das propriedades físicas dos solos residuais oriundos de rochas basálticas foi realizada em campo e em laboratório com ensaios utilizados em Geociências, tanto na Geotecnia como na Pedologia. O objetivo era analisar se as propriedades naturais, aliadas a outros atributos do meio físico, afetam diretamente ou não o desenvolvimento de feiçóes erosivas de grande porte.

Os resultados obtidos através da análise morfopedológica, que incluiu a análise táctil-visual, indicaram nos dois perfis analisados, que os materiais são predominantemente de textura argilosa a muito argilosa e foram classificados pedologicamente como: Nitossolo Vermelho distroférrico, latossólico, textura argilosa no segmento superior (P1) e Nitossolo Vermelho eutroférrico, textura argilosa no segmento mediano (P2). Esses resultados foram corroborados com o ensaio de granulometria realizado em laboratório.

A utilização da técnica de adsorção do corante azul de metileno para identificar o Coeficiente de Atividade dos argilominerais é rápido, eficaz e de baixo custo, sendo um indicativo do tipo de argilomineral presente no solo, que deve ser comparado por outras técnicas (difratometria de raios-X, MEV). Os resultados obtidos indicaram que nos perfis de alteração, os argilominerais presentes pertencem ao grupo da caulinita, que não apresentam comportamentos expansivos.

Os ensaios de erodibilidade apresentaram baixa erodibilidade $(E>1)$ nos dois perfis analisados, corroborando com a textura argilosa obtida em outros ensaios. Quanto aos resultados obtidos no ensaio de infiltração pelo método do duplo anel, constatou-se através da análise táctil-visual que os materiais eram argilosos, o que indicou, teoricamente, que a taxa de infiltração seria baixa. A infiltrabilidade se confirma nos dois pontos onde foram realizados os ensaios, com uma velocidade de infiltração básica de $0,9 \mathrm{~cm} / \mathrm{h}$. De acordo com os resultados obtidos, concluímos que os atributos do meio físico analisados não interferem diretamente no desenvolvimento de feiçóes erosivas de grande porte. Essas ocorrências se devem à interferência de açóes antrópicas, ou seja, quando existe o despejo de águas pluviais concentradas aliada a retirada da cobertura vegetal ou não. Neste caso, o solo residual tende a desenvolver feiçôes erosivas de grande porte. Existe, 
também, outra variável relacionada à estrutura desse material, pois quando microagregado, o material exibe comportamento de material arenoso, portanto é facilmente desagregado. Para a comprovação dessas conclusóes, sugerimos estudos mais detalhados incluindo análises microscópicas do solo residual.

Agradecimentos - Ao apoio financeiro da Fundação Araucária (Apoio ao Desenvolvimento Científico e Tecnológico do Paraná) na Chamada 06/2011.

\section{Referências Bibliográficas}

ASTM-D 3385-88 (1988) - American Society for Testing and Materials. Standard test method for infiltration rate of soils in fields using double ring infiltrometers, $6 \mathrm{p}$.

BALBO, A. J. (2004) - Avaliaçấo da Erodibilidade de Perfis de Solos Residuais da Vertente do CTI/UEM. Relatório Iniciação Científica, (Graduação Geografia), Universidade Estadual de Maringá, 20p.

BERNARDO, S. (1986) - Manual de Irrigação. 4a Ed. Viçosa, UFV, Imprensa Universitária, 488p.

CAMARGO, O. A., MONIZ, A. C., JORGE, L. A. \& VALADARES, J. M. A. S. (1986) - Métodos de análise química, mineralógica e física de solos do Instituto Agronômico de Campinas. Boletim Técnico, 106, 93p.

EMBRAPA (1999) - Centro Nacional de Pesquisa de Solos. Sistema Brasileiro de Classificação de Solos. Rio de Janeiro, 412p.

GEOLOGICAL SOCIETY ENGINERERING GROUP WORKING PARTY REPORT (1990) - Tropical Residual Soil. The Quaterly Journal of Engineering Geology, 23, p. 4-101.

KÖPPEN, W. (1948) - Climatologia. Mexico: Fondo de Cultura Economica, 478p.

LEMOS, R. C. \& SANTOS, R. D. (1996) - Manual de descriçáo e coleta de solo no campo. Sociedade Brasileira de Ciência do Solo - Centro Nacional de Pesquisa de Solos. $3^{\text {a }}$ Ed., Campinas-SP, 83p.

MAACK, R. (1968) - Geografia Física do Estado do Paraná. 1.ed. Curitiba (PR): Banco de Desenvolvimento do Paraná, Universidade Federal do Paraná e Instituto de Biologia e Pesquisas Tecnológicas, 350p.

MORGAN, R. P. C. (1995) - Soil erosion and Conservation. Longman Group Limited, 2a Ed., 298p.

MUNSELL, L. (1975) - Munsell soil color charts. U.S. Dep. Agric. Handb., 18, Soil Survey Manual, Baltimore, 22p.

NÓBREGA, M. T., GUTIERREZ, N. H. M., MENEGUETTE, M. Z. \& FERRAZ, R. L. (2010) - Características geotécnicas de áreas sobre basalto: o caso de Maringá. 70 Simpósio Brasileiro de Cartografia Geotécnica e Geoambiental, anais (CD-ROM), ABGE, Maringá/PR, p.1-14.

PEJON, O. L. (1992) - Mapeamento Geotécnico de Piracicaba, escala 1:100.000: Estudo de Aspectos Metodológicos, de Caracterização e de Apresentação dos Atributos. São Carlos, Tese (Doutorado em Geotecnia) - Escola de Engenharia de São Carlos, Universidade de São Paulo, 2v, 224p.

PINESI, J. P. P. \& NARDI, A. J. R. (2003) - Contexto geológico da Formaçấo Serra Geral no Terceiro Planalto Paranaense. Encontro Geotécnico do Terceiro Planalto Paranaense, anais (CD-ROM), ABMS/ABGE, Maringá/PR, p.1-15

REZENDE, M., CURI, N., KER, J. C. \& RESENDE, S. B. (2005) - Mineralogia de solos brasileiros: interpretaçôes e aplicaçôes. Lavras: Editora UFLA, 192p.

SCHIMIDT, M. F. (2008) - Estudo Experimental da propriedade infiltração: aplicação na vertente do CTI, Maringá/PR. Relatório Iniciação Científica, (Graduação Engenharia Civil), Universidade Estadual de Maringá, 44p. 
SCOTT, H. D. (2000) - Soil water flow processes in the field. In: Soil Phisics: agricultural and environmental applications. Iowa: State University Press, p. 244-281.

SOUZA, V. \& GASPARETTO, N. V. L. (2010) - Avaliação da erodibilidade de algumas classes de solos do município de Maringá - PR por meio de análises físicas e geotécnicas. Boletim de Geografia da Universidade Estadual de Maringá (UEM), 28, p. 5-16.

VIEIRA, P. S. S. (2004) - Caracterização da fração fina dos solos residuais da vertente CTI/UEM: através da adsorção do corante azul de metileno. Relatório Iniciação Científica, (Graduação Geografia), Universidade Estadual de Maringá, 23p. 